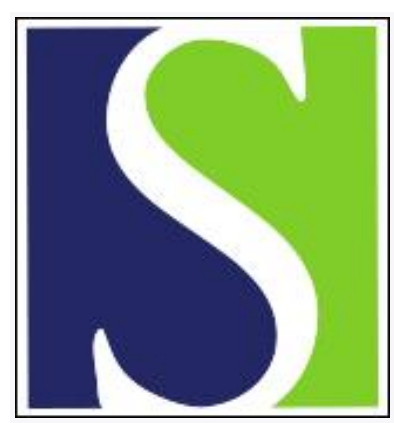

Scand J Work Environ Health 1986;12(4):245-248

https://doi.org/10.5271/sjweh.2143

Issue date: Aug 1986

Usefulness of fingertip skin temperature for examining peripheral circulatory disturbances of vibrating tool operators.

by Kurumatani N, Iki M, Hirata K, Moriyama T, Satoh M, Arai T

This article in PubMed: www.ncbi.nlm.nih.gov/pubmed/3775309 


\title{
Usefulness of fingertip skin temperature for examining peripheral circulatory disturbances of vibrating tool operators
}

\author{
by $\mathrm{N}$ Kurumatani, MD, PhD, ${ }^{1} \mathrm{M}$ Iki, MD, PhD, ${ }^{1} \mathrm{~K}$ Hirata, $\mathrm{MD},{ }^{1} \mathrm{~T}$ Moriyama, $\mathrm{MD}, \mathrm{PhD},{ }^{1} \mathrm{M}$ Satoh $\mathrm{MD},{ }^{2}$ \\ T Arai, $M D^{2}$
}

\begin{abstract}
KURUMATANI N, IKI M, HIRATA K, MORIYAMA T, SATOH M, ARAI T. Usefulness of fingertip skin temperature for examining peripheral circulatory disturbances of vibrating tool operators. Scand $J$ Work Environ Health 12 (1986) 245-248. The data on skin temperature obtained in a cold provocation test (immersing one hand in water at $10^{\circ} \mathrm{C}$ for $10 \mathrm{~min}$ ) were analyzed to confirm their usefulness for examining the peripheral circulatory functions of vibrating tool operators. Under room temperatures from 20 to $23^{\circ} \mathrm{C}$ in winter, the skin temperatures after the end of provocation of the VWF (vibration-induced white finger) group were generally significantly lower than those of the age-matched non-VWF and reference groups, and the non-VWF operators with over $5000 \mathrm{~h}$ of chain-saw experience showed significantly lower skin temperatures 5 and $10 \mathrm{~min}$ after provocation than the age-matched referents. In this study skin temperature was used as a screening test for VWF. The highest sensitivity $(91.1 \%$ ) was obtained at $19.0^{\circ} \mathrm{C}$ at the fifth minute after the end of the provocation, and the highest specificity $(93.3 \%)$ at $15.5^{\circ} \mathrm{C}$ at the third minute after provocation, both the sensitivity and specificity being over $70 \%$ and the correct diagnosis rate being over $80 \%$ among the screening levels.
\end{abstract}

Key terms: cold provocation test, local cooling, screening level, vibration-induced white finger.

Vibration syndrome is now spreading widely in various industries, and methods to diagnose it correctly are required. Several tests (11) have been developed to assess objectively the peripheral circulatory disturbances typified by vibration-induced white finger (VWF). In Japan, the Ministry of Labour recommends a cold provocation test(immersing the affected hand into water at $10^{\circ} \mathrm{C}$ for $10 \mathrm{~min}$ ), and this test is commonly used to check the health condition of operators of vibrating tools, and the fingertip skin temperatures of the provocated hand are measured to assess the peripheral circulatory functions.

Pelmear et al (8) reported previously that skin temperature after local cooling was of no use because a wide overlap was noticed between cases and referents. But the skin temperatures, even those after cooling, depend on the ambient temperatures. Therefore, the validity of the skin temperature results should be evaluated from data obtained under proper ambient temperatures, which make differences clear in the response to the cold stimuli between the subjects with VWF and the referents. Temperatures ranging from 20 to $23^{\circ} \mathrm{C}$ are considered the proper ambient condition from our previous study (2).

This paper describes the skin temperature results obtained under room temperatures from 20 to $23^{\circ} \mathrm{C}$ and discusses the usefulness of skin temperature for ex-

\footnotetext{
Department of Public Health, Nara Medical University, Nara, Japan.

2 Kiwa Hospital, Hashimoto City, Wakayama, Japan.
}

Reprint requests to: Dr N Kurumatani, Department of Public Health, Nara Medical University, 840 Shijo-cho, Kashihara City, Nara 634, Japan. amining peripheral circulatory disturbances of vibrating tool operators.

\section{Methods}

\section{Cold provocation test}

The affected hand of men with VWF, or the right hand of those without it, was immersed up to the wrist joint for $10 \mathrm{~min}$ in water, the temperature of which was regulated to $10( \pm 0.5)^{\circ} \mathrm{C}$ by a water regulation device (Coolnit CL-19, Taiyokogyo). The temperature of the palmar side of the middle fingertip of the immersed hand was recorded by a thermistor thermometer (Takara HD-111) under room temperatures from 20 to $23^{\circ} \mathrm{C}$ before immersion, every minute of the last 5 min during immersion, every minute of the initial 5 min after immersion, and at the 10th minute after immersion. Prior to the test the subjects were asked to sit quietly for at least $30 \mathrm{~min}$ to acclimate to the room temperature. The test was carried out in winter when the various symptoms of vibration syndrome become more serious. The subjects were forbidden to smoke on the test day.

\section{Parameter of vibration exposure dose}

A precise history of chain-saw usage was recorded in interviews with each operator, and the total chain-saw operating time was calculated with the following equation: hours/day $\times$ days/year $\times$ years. The result was regarded as the parameter for the vibration exposure dose (3). 


\section{Statistics}

The differences in the averages of the variables between two groups were evaluated statistically with Student's t-test. The significant level was $5 \%$.

\section{Subjects}

The subjects were 764 forestry workers who had used chain saws and were examined by us in 1982 and 1983 . Out of these, 63 men who suffered from VWF within one year before the test date and 117 men who had never experienced VWF or dysesthesia were chosen as the VWF and non-VWF groups, respectively. In addition to these groups we formed a reference group of 25 male office workers who had never been exposed to vibration occupationally but had been living in an area similar to that of the forestry workers.

\section{Results}

\section{Comparison of serial changes in skin temperature}

Table 1 shows the results of the three groups of subjects. The skin temperatures of the VWF group were significantly lower than those of both the non-VWF and reference groups at all recorded points. The nonVWF group revealed significantly lower skin temperatures at the fourth and fifth minutes after the end of immersion as compared with the reference group. These differences, however, might be ascribed to the wide differences in ages among the three groups.

Therefore, we formed age-matched pairs from the reference, non-VWF, and VWF groups. The non-VWF group was first divided into three groups according to the total chain-saw operating time in an evaluation of the progress of peripheral circulatory disturbances as a function of chain-saw operating time. Thus we obtained five groups, and each group consisted of 19 subjects. The mean ages ranged from 48.4 to 48.8 years, and no significant difference was found between any two groups. Figure 1 illustrates the serial changes of the average skin temperatures of these five groups.

Before immersion the average skin temperature of the VWF group was lower than those of the other groups, but the differences were not significant. During immersion the temperatures of the VWF group were significantly lower than those of the others from the seventh minute to the end. Afterwards the temperatures of the reference group and the non-VWF groups with less than $5000 \mathrm{~h}$ of operating time were similar. In a comparison of these groups, the VWF group showed significantly lower skin temperatures at every recorded point, and the differences became larger with time. The temperatures of the non-VWF group with over $5000 \mathrm{~h}$ of operation time were generally lower than those of the groups with fewer hours and differed significantly from the reference group at the fifth and tenth minutes. But they were generally higher than those of the VWF group, and the differences were significant for the period from the first to the third minute after the end of immersion.

\section{Screening levels of the skin temperatures}

Table 2 shows the screening levels of the skin temperatures for VWF, their sensitivity, specificity, and correct diagnosis rate, which we defined as the rate of diagnosing the subjects by skin temperature. The cases were obtained from the VWF group, and the referents came from the reference group. The ages of the subjects were limited to $45-60$ years to make the age distributions of the cases and the referents similar. The final number of subjects was 45 cases and 15 referents.

The temperature levels listed in table 2 are those with a correct diagnosis rate of over $80 \%$ and those with a sensitivity and specificity of over $70 \%$. No temperature levels before and during immersion exceeded an $80 \%$ correct diagnosis rate, and they were considered useless as a screening test. The temperatures after the immersion had a relatively high sensitivity with a relatively high specificity, though there was no level with

Table 1. Skin temperatures and ages of the operators with and without vibration-induced white finger (VWF) and of the referents.

\begin{tabular}{|c|c|c|c|c|c|c|}
\hline & \multicolumn{4}{|c|}{ Operators } & \multirow{2}{*}{\multicolumn{2}{|c|}{$\begin{array}{c}\text { Reference } \\
\text { group }(\mathrm{N}=25)\end{array}$}} \\
\hline & \multicolumn{2}{|c|}{ VWF $(\mathbf{N}=63)$} & \multicolumn{2}{|c|}{ non-VWF (N=117) } & & \\
\hline & Mean & SD & Mean & $\mathrm{SD}$ & Mean & $\mathrm{SD}$ \\
\hline \multicolumn{7}{|l|}{ Skin temperature $\left({ }^{\circ} \mathrm{C}\right)$} \\
\hline $\begin{array}{l}\text { Before cold provocation } \\
\text { During cold provocationa } \\
\text { After cold provocation }\end{array}$ & $\begin{array}{l}29.3 \\
10.8\end{array}$ & $\begin{array}{l}3.5 \\
0.5\end{array}$ & $\begin{array}{l}30.6 \\
11.2\end{array}$ & $\begin{array}{l}3.1^{*} \\
1.1^{* *}\end{array}$ & $\begin{array}{l}31.1 \\
11.4\end{array}$ & $\begin{array}{l}2.8^{\star} \\
0.8^{\star \star}\end{array}$ \\
\hline $\begin{array}{l}\text { First minute } \\
\text { Second minute } \\
\text { Third minute } \\
\text { Fourth minute } \\
\text { Fifth minute } \\
\text { Tenth minute }\end{array}$ & $\begin{array}{l}12.7 \\
14.0 \\
15.0 \\
15.7 \\
16.3 \\
18.6\end{array}$ & $\begin{array}{l}2.6 \\
2.5 \\
2.6 \\
2.8 \\
3.1 \\
4.3\end{array}$ & $\begin{array}{l}13.6 \\
15.7 \\
17.1 \\
18.3 \\
19.2 \\
22.4\end{array}$ & $\begin{array}{l}2.1^{\star} \\
2.7^{\star \star} \\
3.2^{\star \star} \\
3.7^{\star \star}+ \\
4.1^{\star \star *++} \\
5.5^{\star \star}\end{array}$ & $\begin{array}{l}13.8 \\
16.3 \\
18.2 \\
20.2 \\
21.6 \\
24.5\end{array}$ & $\begin{array}{l}1.9^{\star} \\
2.7^{\star \star} \\
3.7^{\star \star} \\
4.3^{\star \star} \\
5.0^{\star \star} \\
5.8^{\star \star}\end{array}$ \\
\hline Age (years) & 54.7 & 6.3 & 51.4 & $6.7^{\star \star++}$ & 47.4 & $4.9^{\star \star}$ \\
\hline
\end{tabular}

a The average of the skin temperatures recorded from the sixth to the tenth minutes during cold provocation.

${ }^{*} p<0.05$ and ${ }^{* *} p<0.01$ versus the VWF group, ${ }^{+} p<0.05,++p<0.01$ versus the reference group. 


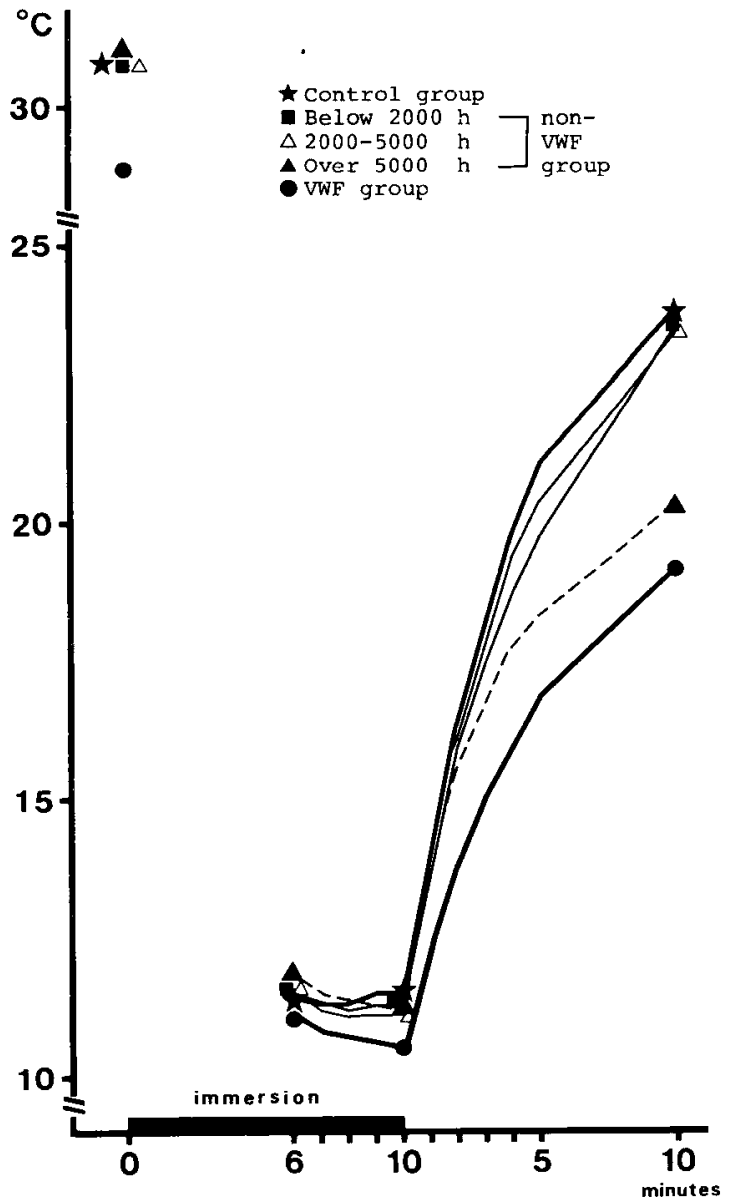

Figure 1. Serial changes of the average fingertip skin temper: atures of the reference group and the operators with (VWF group) and without (non-VWF group) vibration-induced white finger. The non-VWF group was divided into three subgroups according to the sum of the chain-saw operating hours. The ages were matched in each group, and each group consisted of 19 men.

both sensitivity and specificity over $90 \%$. The highest sensitivity and specificity were 91.1 and $93.3 \%$, respectively, when the screening levels were set at $19.0^{\circ} \mathrm{C}$ at the fifth minute and at $15.5^{\circ} \mathrm{C}$ at the third minute after the end of immersion.

\section{Discussion}

\section{Skin temperature comparison between the groups}

The skin temperatures of the VWF group were generally lower than those of the reference and non-VWF groups (figure 1). Okada et al (6) also reported that subjects with VWF show lower skin temperatures than operators without VWF during and after cold provocation, though the water temperature and the provocation period were different from ours. The water temperature of $10^{\circ} \mathrm{C}$ used in the present study is relatively higher than that used usually for a cold pressor test. Recently a significant increase in plasma cyclic gua-
Table 2. Screening levels of the skin temperature for vibrationinduced white finger and their sensitivity, specificity, and correct diagnosis rate after the end of cold provocation. Listed are only those temperatures with a sensitivity and specificity of $>70 \%$ and a correct diagnosis rate of $>80 \%$.

\begin{tabular}{lcccc}
\hline Time $^{\mathrm{a}}$ & $\begin{array}{c}\text { Temper- } \\
\text { ature } \\
\left({ }^{\circ} \mathrm{C}\right)\end{array}$ & $\begin{array}{c}\text { Sensi- } \\
\text { tivity }\end{array}$ & $\begin{array}{c}\text { Speci- } \\
\text { ficity }\end{array}$ & $\begin{array}{c}\text { Correct } \\
\text { diagnosis } \\
\text { rate }^{\mathrm{b}}\end{array}$ \\
\hline Second & 14.5 & 77.8 & 86.7 & 80.0 \\
minute & 15.0 & 86.7 & 80.0 & 85.0 \\
Third & 15.5 & 81.8 & 93.3 & 84.7 \\
minute & 16.0 & 81.8 & 80.0 & 81.4 \\
& 16.5 & 84.1 & 73.3 & 81.4 \\
Fourth & 17.5 & 84.1 & 73.3 & 81.4 \\
minute & 18.0 & 88.6 & 73.3 & 84.7 \\
Fifth & 17.0 & 77.8 & 86.7 & 80.0 \\
minute & 18.0 & 82.2 & 73.3 & 80.0 \\
& 18.5 & 86.7 & 73.3 & 83.3 \\
Tenth & 19.0 & 91.1 & 73.3 & 86.7 \\
minute & 20.0 & 82.2 & 80.0 & 81.7 \\
\hline
\end{tabular}

a Minutes after the end of cold provocation.

b Rate of diagnosing the subjects correctly by skin temperature.

nosine $3^{\prime}, 5^{\prime}$-monophosphate (GMP) was reported in patients with vibration syndrome during and after they immersed their hands in water at $10^{\circ} \mathrm{C}(5)$. Therefore, the difference in serial changes of the skin temperatures between the VWF and other groups in our study might correspond to the difference of the responsiveness of the sympathetic nervous system to local cooling.

The non-VWF operators with over $5000 \mathrm{~h}$ of operating time showed significantly lower skin temperatures at the fifth and tenth minutes after cold provocation than those of the reference group. These results are similar to those of the report of Olsen et al (7) that non-VWF operators with a longer exposure period have lower finger systolic blood pressures than unexposed normal subjects. Azuma et al (1) found that the responsiveness of arterial smooth muscle to noradrenaline increased in animal experiments with an increase in the period of vibration exposure, and Miyashita et al (3) revealed that a clear relationship existed between the total operating time and the VWF prevalence rate in an epidemiologic study. These reports indicate that the repetitive exposure to vibration makes the responsiveness of the vessels to cold greater and finally brings about VWF. It should be emphasized that the skin temperatures after our cold provocation test can be used to detect hyperresponsiveness to local cooling in the operators before the initial VWF attack.

\section{Screening levels for vibration-induced white finger}

Among the screening levels listed in table 2, the highest sensitivity and specificity were 91.1 and $93.3 \%$, respectively, with an $85 \%$ correct diagnosis rate. A traditional cold provocation test can detect about 40 to $95 \%$ of the men with a history of VWF (9), and these levels are almost equal to those found in our study on sensitivity. But the procedures used in most cold prov- 
ocation tests are generally time-consuming and not suitable for a population study. Recently a method to measure finger systolic blood pressure was developed (4), and Olsen et al (7) applied this method to detect VWF. They reported that the sensitivity and the specificity were $92 \%$ and $81 \%$, respectively, and that the pressure was significantly lower in subjects with severer VWF. Skin temperature is inferior to finger systolic blood pressure in specificity. But skin temperature can discriminate between referents and non-VWF subjects with longer tool operating time equally as well as finger systolic blood pressure, and measuring the latter is somewhat troublesome because a cooling blanket perfused with water at $10^{\circ} \mathrm{C}$ is necessary. Therefore, our method is considered more satisfactory for a population study than other cold provocation tests or the measurement of finger systolic blood pressure.

The VWF operators showing relatively high skin temperatures were false negatives. The color of the skin depends on the quantity of blood present in the subpapillary plexus, while the temperature of the skin depends chiefly on the rate of flow through the whole skin (10). Therefore, when arteries, arterioles, and venules are dilated but the subpapillary capilaries are not, the skin can be warm and pale. In the same manner, the false negatives might be those whose responsiveness of the precapillary sphincter to cold stimuli increases but not that of the vessel smooth muscles. On the other hand, the false positives were the subjects who had never been exposed to vibration and showed relatively low skin temperatures. This phenomenon occurs mainly because of the large differences in skin temperatures among individuals. Whether or not these false positives are a high risk group with respect to vibration exposure is interesting however. A prospective study is necessary to determine this point.

\section{References}

1. Azuma T, Ohhashi T, Sakaguchi M. Vibration-induced hyperresponsiveness of arterial smooth muscle to noradrenaline with special reference to Raynaud's phenomenon in vibration disease. Cardiovasc Res 12 (1978) $758-764$.

2. Kurumatani N, Ogoshi K, Aoki Y, Moriyama T, Tomii $\mathrm{S}$. Effects of immersion of hand in cold water $\left(10^{\circ} \mathrm{C}\right.$ for $10 \mathrm{~min}$ ) on the finger skin temperature of chain saw operators under different room temperatures [in Japanese]. Jpn J Ind Health 23 (1981) 310-311.

3. Miyashita S, Shiomi S, Itoh N, Kasamatsu T, Iwata $H$. Epidemiological study of vibration syndrome in response to total hand-tool operating time. Br J Ind Med 40 (1983) 92-98.

4. Nielsen ST, Lassen NA. Measurement of digital blood pressure after local cooling. J Appl Physiol 43 (1977) $907-910$.

5. Okada F, Honma M, Ui M, Kiyota N. Plasma guanosine $3^{\prime}, 5^{\prime}$-monophosphate responses to the cold pressor test in patients with vibration disease. Arch Environ Health 38 (1983) $144-147$.

6. Okada A, Yamashita T, Ideda T. Screening test for Raynaud's phenomenon of occupational origin. Am Ind Hyg Assoc J 33 (1972) 476-482.

7. Olsen N, Nielsen SL, Voss P. Cold response of digital arteries in chain saw operators. $\mathrm{Br} \mathbf{J}$ Ind Med 38 (1981) 82-88.

8. Pelmear PL, Taylor W, Pearson JCG. Clinical objective tests for vibration white finger. In: Taylor W, Pelmear PL, ed. Vibration white finger in industry. Academic Press, London 1975, pp 53-81.

9. Pyykkö I. The hand-arm vibration syndrome: Definitions and assessment of symptoms. J Low Freq Noise Vibration 1 (1983): special issue, 6-18.

10. Rothman $\mathrm{S}$. The color of the skin as influenced by circulation. In: Physiology and biochemistry of the skin. The University of Chicago Press, Chicago \& London, 1965, pp 69-72.

11. Taylor W, Brammer AJ. Vibration effects on the hand and arm in industry: An introduction and review. In: Brammer AJ, Taylor W, ed. Vibration effects on the hand and arm in industry. John Wiley \& Sons, New York, NY 1982, pp $1-12$. 